\title{
Síntomas y Consecuencias de la Rebelión de Túpac Amaru.
}

\author{
(A la memoria de don \\ Carlos Wiesse).
}

\section{INTRODUCCION $\square$ SINOPSIS}

El Virreynato del Perú era una estructura perteneciente a otra estructura mayor, representada por el Imperio español.

Formaba parte del Virreynato y dependía en lo religioso del Obispado del Cusce, el Corregimiento de Tinta, uno de cuyos Cacicazgos eracen de Pampanarca-Surimana-Tungasuca. Por los años de 1775 tomaba el título de Cacique don José Gabriel Tupac Amaru, quién buscando justicia contra los desmanes de las malas autoridades, y no siéndole dado hallarla, se levanto, apresando a su corregidor don Antonio de Arriaga, la noche del cuatro de noviembre de I780. Esta decisión del Cacique dió como consecuencia la realización del movimiento armado más importante del siglo XVIII, y cuyas repercusiones, propagándose hacia el sur, conmovieron la región del Kollao e intensificaron y confirieron sentido a los disturbios de los hermanos Catari -en la futura Bolivia. 
Gobernando en Lima el virrey don Agustín de Jáuregui y en Buenos Aires el virrey don Juan José de Vértiz, siendo ministro de Marina e Indias don José de Gálvez y rey de España dcn Carlos III, el cacique Tupac Amaru fué vencido por las tropas realistas - mayormente formada por Indios-, al mando del mariscal de campo don José del Valle, acompañado por el visitador don José Antonio de Areche - en representación del Virrey. La expedición pacificadora y punitiva, era repetida en 1782 - con la sola presencia de del Va1le. De manera simultánea se efectuaba la pacificación de los territorios de la jurisdicción de Buenos Aires, mediante los esfuerzos de don Ignacio Flores y de don José Reseguín jefes' militares designados por Vértiz.

Iil altivo Cacique (apellidado Túpac Amaru por descender en línea recta materna del último Inca de ese nombre, perteneciente a la dinastía de los Hanan-cuscos - ajusticiado por el virrey Toledo en el siglo XVI) tomó la iniciativa, sin desconocer la autoridad del Rey. Vencedor en los comienzos', prefirió retroceder al sur-y enviar tropas a las provincias que miran al oriente, bajo la dirección de su primo hermano Diego Cristobal, tratando de extender su movimiento justiciero. "Cuando se decidtó a sitiar sqa ciudad del Cusco ya era tarde. Un socorro inicial, enviado a marchas forzadas desde Lima, permitía a los defensores repeler el ataque de Túpac Amaru —en los primeros días de I78I.

La presencia del grueso del ejército, su aumento a I7,000 hombres y su previo adiestramiento, señalan el ocaso del Caudillo. Vencido en combates sucesivos, fué traicionado y condenado a muerte- en compañía de sus parientes y partidarios, obedeciéndose a lo mandado por cruelísima sentencia.

Sin embargo, la sublevación continuó con mayor encarnizamiento en el sur. Diego Cristóbal tomó la dirección de 
la lucha, hasta que seducido por un tratado falaz aceptó el perdón general. Y leal a su compromiso acompañaba al mariscal de campo del Valle en la segunda campaña pacificadora. Un año después subía al cadalso. En La Paz y provincias adyacentes surge la importante figura de Túpac Catari, vencido y ajusticiado después' de dos memorables asedios contra la ciudad — defendida por don Sebastián de Segurola. Los jefes de la represión de Lima y de Buenos Aires se daban la mano en el preblo de Achacache - a mediados de i782. Como brote postrero y alejado, surge la figura de don Felipe Velasco Túpac Inca Yupanki, vencido en Huarochirí y ejecutado en la plaza mayor de Lima en julio de I783. Y en todo el movimiento posterior a su muerte, la figura de Túpac Amaru es mencionada por los jefes rebeldes: ya como Virrey de. Lima o como Señor del Gran Paititi, porque en su persona y fama inmortales afinca la continuidad del movimiento.

Del exterminio de los' parientes de Túpac Amaru, salvaron los hijos menores Mariano y Fernando y su medio hermano Juan Bautista. Mariano murió camino al destierro. Fernando, en España eafgunos años mâs tarde. Juan Bautista logró regresar autierras de América en I822. Habiendo desembarcado en Buenos Aires - y con apoyo del gobierno argentino -, llegó a escribir, ya oetogenario, sus Memorias, interesantítimo y trágico documento.

Breve el momento principal del Caudillo, honda la reacción en la masa indigena, este movimiento repercute en todas las clases y en todos los dominios españoles de la América meriodinal, gravando en la imaginación de las gentes la visión de su gesto magnífico. Por esto, el movimiento del cacique mestizo Túpac Aamaru es el lapso reformista, todavía sediento de la justicia del Rey, pero ya como una actitud antagónica a toda sumisión incondicional, y que repercuitia 
por primera vez en la totalidad del ámbito colonial. Y allí comienza el Momento de la Emancipación.

Y cuando se contempla la totalidad de este acontecimiento histórico, un claro dualismo se hace presente: por un lado, la reacción fidelista del Caudillo, quién protesta contril las malas autoridades, creyendo no obstante en la insobornable justicia del Rey; y por el otro, la decidida actitud de la masa indígena que llegó a creer, férvidamente, en una pronta y absoluta liberación; o se opuso, siguiendo al odio o el interés de los Caciques fieles.

\section{SINTOIMAS}

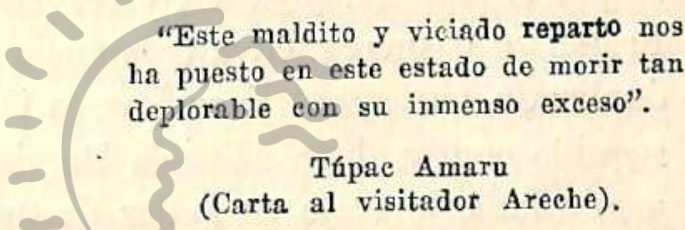

En las cartas y edictos de Túpac Amaru se exponen con claridad los síntomas del levantamiento iniciado el cuatro de noviembre de 1780 . Que la autoridad real es paternal y justa, lo prueban las leyes de Indias. Pero que permanecen incumplidas, lo demuestra la diaria conducta de las autoridades y la desesperación de los Indios. Levantarse contra ellas era defender al Monarca. Un subterfugio de gran efecto entre los naturales', fué apoyar sus acciones invocando una supuesta comisión del rey, aunque Túpac Amaru esquivó inteligentemente todo comentario, dando como única razón de su conducta el mandato real de proceder "extraordinariamente contra varios corregidores y sus tenientes, por legítimas' causas que por ahora se reservan". Y en otro lugar a firma: "aunque hoy se me note de traidor y rebelde, infiel y tirano a nuestro Monarca Carlos, dará a conocer el tiempo que 
soy su vasallo". Los bandos y edictos publicados y difundidos eran pués', únicamente para que nadie alegase ignorancia de los reales deseos y con el "único ánimo de cortar el mal gobierno de tanto ladrón”. Como solución adecuada, aboga por los nombramientos de Alcaldes mayores "de la misma nación indiana" con un moderado sueldo; la cesación de los Repartos mercantiles y de algunas odiosísimas contribuciones, con lo que se debilitaría el verdadero nervio del general descontento; y que la ciudad del Cusco fuese la s'ede de una nueva Real Audiencia, residiendo "un Virrey como presidente, para que los indios tengan más cercanos los recursos". Esto parece desvirtuarse por un bando firmado en Tungasuca por el rey "D. José I", y refrendado por s'u secretario Francisco Cisneros, cuya existencia se confirma por un cuasi duplicado, que apareció en Nueva Granada. Y por el proceso seguido contra doña Micaela Bastidas, quien contes'tó vagamente haberlo visto en poder de un Cacique de Marcapata. Como su tenor contradice la actitud general de Túpac Ama$\mathrm{ru}$, provisionalmente aquel bando puede interpretarse o corino una manerade impresionar sectóres muy alejados o como recurs'o deses̄peradolenclosltienuposecercanos al desastre o como una oportuna concesión al sector extremista o inconsciente del camino que debía seguirse para triunfar. Por el con trario la tendencia a servirse de los esclavos, prometiéndoles' la libertad si ayudaban a la rebelión, aparece desde los prime-ros momentos. Dentro de la perspectiva de Túpac Amaru se justificaba su inclusión y el premio de liberarlos, porque al colaborar en la lucha contra las malas autoridades cumplían los deseos' del monarca, realizando una obra benéfica al reino. Ejemplo individual - entre otros —es el de don Antonio Oblitas, esclavo de color del corregidor Arriaga, luego su verdugo, siguiando fielmente la suerte de la rebelión. 
Con respecto a la Iglesia sucedía cosa análoga. Educado Túpac Amaru por sacerdotes, teniendo como amigos y confidentes a miembros del clero, no era su religiosidad moneda fingida sino actitud natural. Pensaba que la religión ca. tólica debía permanecer, afirmando reiteradamente que las iglesias, monasterios, sacerdotes y religiosas "tendrían el aprecio debido a su estado". Durante el sitio del Cusco, escribió al Obispo que admitidos sus reclamos se retiraría "a una Tebaida a donde pida misericordia, y US. I. me imparta todos los senderos documentos para el glorioso fin, que mediante la divina misericordia espero, a cuyo fin aspiro". Y en su protesta ante el Cabildo del Cusco sobre incumplimiento de los usos de la guerra, señala como acción muy censurable el que se ahorquen $\sin$ confesión a sus hombres. Esto no le impedía recordar que, muchos sacerdotes debían ser expulsados de las poblaciones por que olvidaban sus deberes y se dejaban arrastrar por las' pasiones mundanas, aumentando el sufrimiento de los indios, a quienes precisamente debían escudar.

Contradiciendo opiniones segundas, el hombre indígena había sido externamente vencido pero no absorbido y ni siquiera totalmente donninado.íla reacción de los naturales aparece desde el comienzo de la conquista y está simbolizada en la actitud del general Calcuchímac, dejándose quemar en la hoguera antes que abjurar de sus dios'es tutelares. La reacción de Manco II es altivamente continuada hasta los tiempos del virrey Toledo. Ya en ${ }^{56} 65$ existen noticias de un levantamiento que debía abarcar todo el Virreynato. El peninsular don Felipe de Segovia - fundador del obraje de la Mejorada, en el valle de Jauja-, comunicó la noticia al gobernador del Perú don Lope García de Castro. Parece que el golpe debía comenzar el día jueves santo, "al tiempo que anduviesen las procesiones de la disciplina por las ca- 
lles". Una nueva conjuración fué descubierta en Lima cl año i666. Los conjurados debían "pegar fuego a la ciudad por muchas partes, y soltar el agua de la acequia grande de Santa Clara". En I742 Juan Santos se levantaba en las montañas de Chanchamayo, muriendo catorce años más tarde sin haber podido ser derrotado por las tropas del Virrey, permaneciendo en las leyendas de los naturales la creencia en su resurrección. Finalmente, en I750 brotaba en Lima una conjuración. Delatada, uno de los comprometidos, don Francisco Inca, se levantó en Huarochirí. Y aunque el rebelde fué vcncido, las autoridades quedaron muy alarmadas por la audacia que suponía un levantamiento casi en el foco del poder español. Esta mención sucinta, acredita la constante resistencia explícita e implícita de los indios y el favorable terreno para todo movimiento de protesta.

Tampoco puede achacarse al indio incapacidades y vicios insalvables. La historia del Imperio incaico contradice tan peregrina afirmación. El español don Sebastián Lorente ha escrito un justo enjuiciamiento sobre la conducta de los rebeldes: "En chanto tala fiereza de los alzados, tan optiesta a la dulzura de caráeter, qutul disting tue a easi todos sus linajes, procedía del odio concentrado a sus opresores, de la falta de cultura evangélica y de su antisocial aislamiento. Los que vivían en apartadas estancias o en quebradas ignoradas, huían del trato casi siempre hostil de las otras razas, como hutye la tímida vicuña del cazador sin misericordia; en el seno mismo de las poblaciones se aislaban los indios por el uso de un idioma diferente, por sus costumbres' de otro tiempo y por las violencias y menosprecio de que eran objeto. Convertidos por la servidumbre en simples instrumentos' de la fuerza bruta, no podian menos de cumplir con ciega sumisión los bárbaros designios de los' que se ofrecian desagraviarles para con- 
vertirse en tiranos de la peor especie. La responsabilidad de sus mayores excesos recaía, en gran parte, sobre los que les habian reducido a condición tan abyecta. Sin embargo, todavía los que sólo juzgan por las apariencias, los partidarios del rigor y los interesados en una explotación inicua condenaban a los indios' a una perpetua servidumbre, considerándola como una raza perezosa, incapaz de cultura, ingrata y llevada sólo por el mal tratamiento. Es la perpetua calumnia de todas las castas opresoras contra las razas oprimidas; las embrutecen con su tiránico yugo, y luego las declaran indignas cle la libertad por los vicios', que nunca dejará de inocular la irracional sujeción, que hace depender unos hombres de otros, como del espíritu depende la materia. ¡Perezosos los indios, a quienes se debía toda la cultura física del país; perezosos los que menos oprimidos en las ciudades, eran modelos del industrioso artesano; los que redoblaban sus tareas de día y de noche, cuando les halagaba la esperanza de gozar el fruto de sus sudores! ¿Estúpidos los que, lejos del mundo civilizado, habían levantado la esplendente cultura de los Incas, y en el seno de la opresión se honraban con hermanos eminentes en la cátedra, en el púlpito y en el ejercicio de las profesiones que exigen más genio!". Hasta aqui, Lorente.!

Lo anterior ha sido complementado con otros motivos, insistiéndose en la participación de los Jesuitas y la acción directa de los agentes de Inglaterra. Los Jesuitas estaban enemistados con el gobierno español, a raíz de su expulsión decretada en 1767 . Sin embargo, su influjo no aparece en la rebelión de Túpac Amaru. El papel que pudo corresponder al jes'uita don Francisco José Marcano y Arismendi (considerado en una carta de junio de I78I como hermano de Far- 
fán de los Godos), está refutado por el examen teológico a que fué sometido el diecisiete de abril de r780. La superchería terminó ante el veredicto negativo de su calidad de sacerdote, dado en Buenos Aires por un jurado compuesto por don Juan Cayetano Fernández de Agüero, cura rector más antiguo de la Catedral; don Pedro Vega, presbítero Fiscal del Obispado; y de don Manuel Echevarría, presbítero capellán del Virrey. 'Marcano fué enviado preso a la península, pero el barco en que viajaba cayó en manos de los ingleses. La afirmación que hizo entonces de alzamientos para octubre de I780 ha querido ser vista como un anuncio de la rebelión de T'úpac Amaru. Sin embargo, cabe afirmar que sus predicciones se refirieron al estallido del movimiento de Farfán de los Godos -descubierto antes de brotar y cuya realización debía efectuarse a fines de agosto. Además, su dilatado viaje hasta Buenos Aires le permitió auscultar el ambiente, comprendiendo que el movimiento del Cusco sería recibido con general satisfacción. Cuando Marcano volvió con ayuda de los ingleses', no logró pasar al Perú por haber sido oportunamente arrestado por los españoles y enviado a una prisión de España. En sintesis: Marcano no fué Jesuiia, ni logró pasapraterú después de su contacto con los ingleses.

Otro pretendido hijo de San Ignacio, don Anselmo de Alvisto y Samalloa, natural de Paucartambo, y en relaciones con Túpac Amaru, ha mostrado su falsedad por declaración propia. Apresado en julio de 1783 , confesaba en el interrogatorio judicial "que ni es tal Eclesiástico, ni religioso de ninguna religión, que es puramente seglar", vistiendo el hábito con ocasión de estar huídos de sus Doctrinas muchos eclesiásticos. El jesuita Vizcardo y Guzmán considera en su Carta, que la expulsión de su Orden tuvo como origen la codicia del gobierno español. Agregando, que "sin compasión 
a la desastrada situación quiso aún agravarla con nuevos impuestos, particularmente en la América meridional, en donde en I780 costaron tanta sangre al Perú". Considera Vizcardo que el movimiento de los Comuneros en Nueva Granada tuvo en parte los abusos de las autoridades y menciona vagamente el de Túpac Amaru. Este juicio puede ser una nueva confirmación de la ausencia de influencia jesuítica en la rebelión de Tinta.

Con respecto a la participación de Inglaterra, es' menester recordar que por este tiempo se haliaba en guerra contra España. El virrey Guirior en su relación alude ligeramente a la "guera con la nación británica". Su sucesor Jaúregui escribe con mayor detenimiento sobre el peligro de una expedición marítima del "almirante inglés Eduardo Huges, que salió de Inglaterra con una escuadra para el golfo de Bengala con la idea de arrojarse sobre las costas de Chile y de este reino". Esto motivó que Jaúregui no comandara las tropas que marcharon contra Túpac Amaru, debiendo permaneccr. necesariamente en Lima "como el centro de las demás poblaciones para concurrir, a todo oportunamente, y hallarme ocupado en la provision de las plazas de Chiloé y Valdivia".

En los documentos referentes a la rebelión de I780. existen tres breves alusiones a la participación o presencia de súbditos ingleses. La primera, consiste en una noticia de un Diario arequipeño de enero, en $I 780$, informando que al entrar Túpac Amaru en la población de Azángaro "traía a su lado cuatro hombres enmascarados, los que no trataban con ninguno", agregando que esto se relacionaba con las declaraciones de un señor Zavala afirmando cómo "al lado izquierdo y derecho de Túpac Amaru, iban dos hombres rubios' y de buen aspecto, que le parecían ingleses". La segunda, es' un documento masónico firmado por Túpac Cateri al lado de apellidos ingieses - aunque la fecha del documento 
es muty posterior. Lo cual llevaría a la interrogación acerca de la importancia efectiva de las asociaciones masónicas como intermediariąs de la acción inglesa en la rebelión, máxime si recordamos la existencia de grupos masónicos desde mediados del siglo XVIII. Es decir, sobre la actividad mediata de Inglaterra. En último lugar está la certificación del cura don Bernardino de Uria Illanes, de 5 de enero ( 1782 ), en donde se afirma la entrada de varios sujetos en su despacho, uno de los cuales' resultó llamarse Mariano Túpac Amaru. Y entre sus hombres llevaba a "un Ing!és vatidor de Bandera". Por ahora puede considerarse que Inglaterra ha sido "la nación que en mayor grado y más prácticamente, colaboró en la independencia de América. Colaboración que tiene dos' aspecctôs: uino heróico y otro diplomáticos; sutil, lento y perspicaz éste, y de la más segura eficacia para el porvenir de las colonias insurrectas, incomparablemente gallardo el otro, y enaltecido por los más saltantes episodios de la serenidad y de la bravura", escribe Porras Barrenechea.

\section{Biblioteca de Letras}

Los virreyes de Rimaiy deiBuenos Ares se han pronunciado sobre los precedentes de tan peligroso movimiento. E1 virrey Jaúregui creía que el origen parcial de la rebelión estaba en el exceso de los repartos, abusos en el trabajo de las minas y recargados pechos. Esto se completaba con el estado de barbarie en que se encontraban los naturales - fomentada implícitamente por los españoles -, propensos a creer en las promesas por ilusorais que fueran. Y el estado de "indefen. sión" de las provincias del interior. Sin embargo, reconoce el Virrey que en Lima los indios civilizados "acreditan una fiel y arreglada conducta en todos los destinos a que se aplican, observấndose, aún con los de la sierra, que son sensibles 
a los beneficios y los reconocen, de que hay muchos ejemplos en los corregidores pués cuando los han tratado bien la correspondencia ha sido igual, vertiendo lágrimas al tiempo de su retiro". El virrey de Buenos Aires, Vértiz, escribía en octubre de I780, refiriéndose a los sucesos de Chayanta, ser claro "que la opresión y despótico proceder del corregidor ha excitado aquella sublevación o movimientos populares; y ciue si la Audiencia hubiera prestado atención a la carta que la dirigió el Gobierno, no hubieran sobrevenido los conflictos en que se le pone la apatía y desatención de unos asuntos tan recomendables, y por cuyo remedio por la exacta administración de justicia, deben precaverse". En abril del año siguiente señalaba el ministro de Indias los antecedentes verdaderos, pues "con generalidad se atribuyen a distintos motivos de opresión, que advierto se varían según los intereses de cada uno" representadas por los excesos en los repartos, mitas, impuestos múltiples, no habiendo "influído menos la novedad de empadronar los cholos y zambos”.

\section{Bibliotecade Letras}

E1 levantamiento habia madurado más en el alma del cacique Túpac Amaru, que exteriormente en efectivas comexiones anudadas en sus múltiples viajes. Esto obedecía al temor de ser prematuramente delatado si confiaba sus' proyectos a personas, cuyo parcial descontento no era garantía de absoluta fidelidad. El circunstanciado conocimiento de las condiciones que imperaban en el territorio, lo había adquirido Túpac Amaru pesquisando por su "propia persona en la mayor parte del reino el gobierno espiritual y civil de estos vasallos". La ocasión propicia aparecía pues, con el entrecruzamiento de situaciones que debilitaban a las autoridades: la guerra contra los' ingleses, la repercusión del fa- 
llido intento de Farfán de los Godos en el Cusco y la noticia de los' disturbios de Chayanta, el aumento de contribuciones e intento de empadronar como tributarios a razas que habían permanecido exentas, o la discusión acerbísima entre las autoridades reales y eclesiásticas, encabezadas por el Obispo del Cusco y el Corregidor de Tinta.

\section{CONSECUENCIAS}

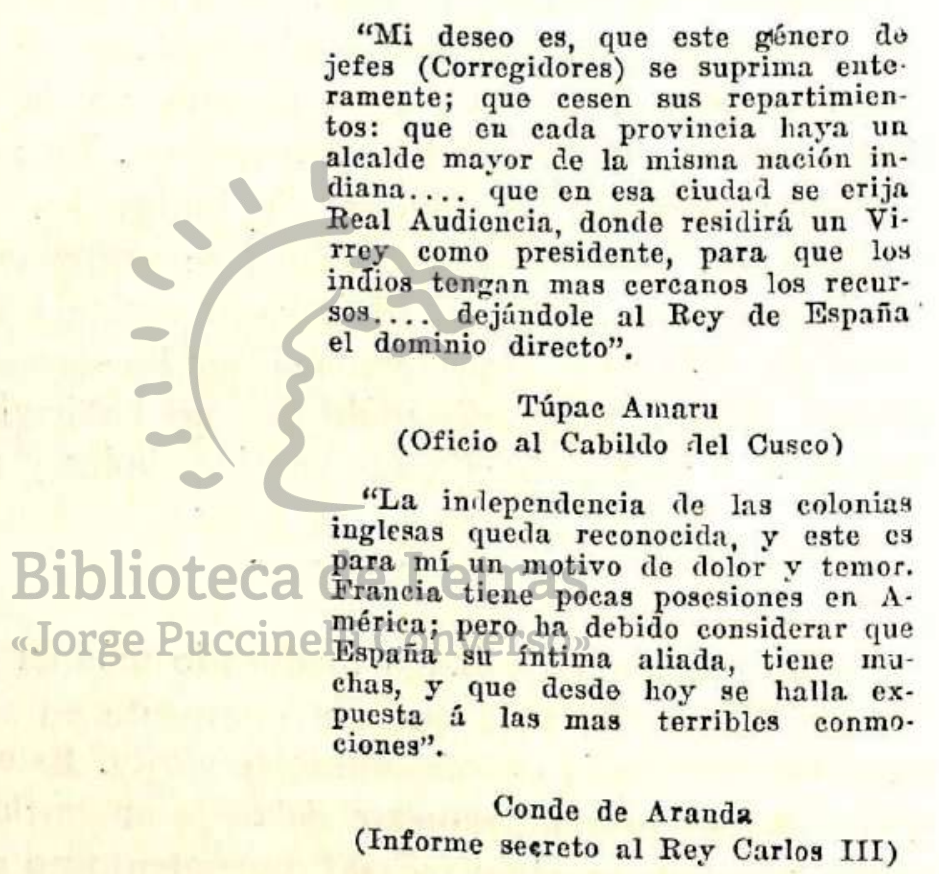

Ia rebelión del cacique Túpac Amaru originaba consecuencias simultáneas a su desarrolio, y otras que fueron realizándose con normal posterioridad.

En una carta enviada desde Orcoruro el tres de enero de $178 \mathrm{I}$, se encuentran las peticiones fundamentales de Túpac Amaru, y que en lo principal realizó más tarde Carlos III. Manifestaba textualmente: "Mi deseo es, que este gé- 
nero de jefes (Corregidores.-C.V.) se suprima enteramente; que cesen sus repartimientos; que en cada provincia haya un alcalde mayor de la misma nación indiana, y otras personas de buena conciencia, sin más inteligencia que la administración de justicia, política cristiana de los indios y demás' individuos, señalándoseles un sueldo moderado, con otras condiciones que a su tiempo deben establecérseles entre las que es indispensable una comprensiva a que en esa ciudad se erija Real Audiencia, donde residirá un. Virrey como presidente, para que los indios tengan más cercanos los recursos. Esta es toda la idea por ahora de mi empresa, dejándole al Rey de España el dominio directo que en ellos ha tenido, sin que se les substraiga la obediencia que les es debida, y tampoco el comercio común como nervio principal para la conservación de todo el reino".

Medida inicial de la Junta de Guerra del Cusco fué indultar a los que abandonasen las' banderas de Túpac Amaru, y eximir de los repartos mercantiles, aduanas, alcabalas y servicios odiosos a los indios fieles. Era la fórmula circunstancial y oportuna de las autoridades: efectuar concesiones que dividian a los, indios en los momentos de peligro, para invalidarlas calladamente cuando los tiempos se normalizaban. Sin embargo, ante la gravedad de los sucesos el virrey Jáuregui tomaba medidas radicales. Considerando que los Repartos mercantiles eran motivo principalisimo en los disturbios y la esperanza de su extirpación los impelía a seguir las banderas de Túpac Amaru, "pareció que era llegado el caso de resolver su absoluta prohibición". En el Acuerdo de siete de diciemtıre ( 1780 ), asistiendo el visitador Areche, quedó aceptada la propuesta del Virrey, con la sola condición de poder cobrarse el valor de las' mercaderías últimamente repartidas, sin excesos ni renovados agravios. Para velar 
por el perfecto cumplimiento de tales disposiciones fué erigida una Sala de Desagravios - compuesta por miembros de la Real Audiencia de Lima. Bandos y cartas- circulares debían publicar los acuerdos. A principios de enero (cuando Túpac Amaru sitiaba la ciudad), el obispo Moscoso recibia los ejemplares' enviados desde Lima.

En el texto de la sentencia contra Túpac Amaru se adjuntan consideraciones dirigidas a prevenir futuros levantamientos y fomentar el olvido de las tradiciones autóctonas. La ciudad del Cusco recibia el calificativo de "Fidelísima y muy leal", como reconocimiento a sus esfuerzos contra la rebelión. En lo sucesivo, las autoridades tuvieron prohibición absoluta de recibir informaciones sobre descendencia de nobles indígenas sin permiso real. Las realizadas hasta entonces carecerían de valor sino lograban obtener la confirmación del Monarca. Así mismo, los Indios principales quedaron prohibidos de firmar añadiendo e! título de "Incas", por la grandísima impresión que producía esta denominación entre los naturales, "mandándose, como se manda, a todos los que tengan árboles genealojícos'e documentos que prueban en alguna manera sus descendencias con ellos, ieloque manifiesten o remitan certificaciones con ellos, y devalde y por el corrieo, a las respectivas Secretarías' de ambos 'Virreynatos, para que allí se reconozcan sus solemnidades por las personas que deputen los Excmos. Señores Virreyes, consultando a su S. M. lo oportuno, según sus casos; sobre cuyo cumplimiento estén los corregidores muy a la mira, solicitando o averiguando quien no lo observa". El cargo de Cacique sería personal y no hereditario - como hasta entonces. - Y en los pueblos los Caciques serían sustituídos por Alcaldes' electivos, escogidos entre los que hablaban el castellano y tuvieran buenas' costumbres.

Tratando de alejar a los naturales "del ódio que han 
conservado contra los españoles, y sigan los trajes que les señalan las leyes', se vistan de ntwestras costumbres españoles y hablen la lengua casteliana, se introducirá, con más vigor que hasta aquí, el uso de sus escuelas, bajo las penas más rigurosas y justas contra los que no las usen, después de pasado algún tiempo en que la puedan haber aprendido". Los indios nobles estaban prohibidos de vestir al uso del antiguo imperio, debiendo los Corregidores' recoger las ropas que permaneciesen en poder de los particulares. Igualmente debían borrar o entregarse-las pinturas o retratos de los Incas "en que abundan con estremo las casas de los indios que se tienen por nobles para sostener o jactarse de su descendencia”. Igual labor debía realizarse en las iglesias', monasterios, hospitales y otros lugares, sustituyéndolos por la efigie del monarca o de antecesores.

Quedaban prohibidas las representaciones de obras teatrales que recordaban los tiempos del antiguo Imperio Incaico. Igualmente el uso de Pututos, que son "unos caracoles marinos de un sonido estraño y lúgubre, con que anuncian el duelo y lamentable memoria que hacen de su antigüedad". El uso de trajes negros como recuerdo de-sus difuntos Incas, o como lamentordel tiempo de faoconquista, que "ellos tienen por fatal y nosotros por feliz". Y en terreno más peligroso, se prohibía las fábricas de cañones, lo mismo que las de pólvora, cuya abundancia y descontrol en "haciendas, trapiches y obrajes era nociva a la paz".

Desde antes de 1780 se notaba en el campo intelectual la tendencia a la eliminación de ciertas obras'. El estudio de los escritos de fray Bartolomé de las Casas fué restringido, y prohibida la Historia de la América del escosés Robertson por su calidad de protestante, aunque realmente era por 10 contenido en los libros tercero, cuarto y séptimo, que hablan de la crueldad de los conquistadores en la Española, desgo- 
bierno, inexperiencia y codicia en el manejo de los natura!es; descripción de las culturas autóctonas; y cuadro de las cos-tumbres e instituciones de los Peruanos y Mejicanos respectivamente. Con aquel precedente, el visitador Areche escribia al gobierno español, el primero de mayo de I78I, sugiriendo que se prohibiese la lectura de los Comentarios Reales de Garcilaso de la Vega Chimpuocllo, por perjudicial a la sumisión del reino, obteniendo contestación favorable en agosto de 1783 . Y secretamente se recogía el altivo Elogio de Baquíjano y Carrillo al virrey Jáuregui.

Realizada la ejecución de Túpac Amaru, el visitador publicaba un "general indulto a todos los arrepentidos de su error de haber sido partidarios del rebelde se acogiesen de las banderas y obediencia de V. M., empeñando su Real palabra a su cumplimiento, de que se reservaban los que hacían de. cabesa y eran principales movedores de la rebelión, de cuyos nombres se hizo clara expresión, para que no dudasen todos los demás de la verdadera concesión de aquella gracia”.

A pesar de la alarmante disminución de los impuestos, languidez de la industria, comercio y agricultura, el virrey Jáuregui señaló dạ dificilísimal situación de los indios que luchaban contra la rebelión y carecían de recursos para abonar los tributos. Y tomando como base lo estampado en la Reco. pilación, enviaba al Visitador: un escrito sobre exención de tributos por un año. La respuesta de Areche fué favorable, y añadía la sugerencia de un perdón general. Como consecuencia, el doce de septiembre de I78I Jáuregui expedia un bando con ambas resoluciones. A los jefes que prudentemente pedian el indulto mediante una Real Cédula, se les contestó que bastaba con lo efectuado.

La ejecución de las resoluciones creaba dudas en los funcionarios. E1 Administrador general de rentas unidas 
del Cusco escribía al subdelegado Ordozgoyti, cómo de aquelia resolución transmitida "a todos los Corregidores de las provincias del distrito de esta administración general para que se haga notorio a los indios rebeldes y los demás que se mantienen en la actualidad sin esta inquietud, resulta, precisamente, el que unos y otros se excusen al pago del real tributo y de consiguiente, los Corregidores sin arbitrio alguno para ejecutarlos al pago, no obstante de que se hallan reconvenidos por esta administración general, de antemano, con respecto a los dos semestres que se hallan debiendo en el día de Navidad de ochenta y San Juan de ochenta y uno". Con la exención de tributos quedaban beneficiados los rebeldes y lesionado los' indios fieles. Aunque sofísticamente manifestaba el Contador "que a los mismos indios fieles a nuestro soberano en las provincias pacíficas, con la dispensa del tributo, aunque temporánea, se les haría notable injuria, pues se les incluia en un temperamento o medio gue es destructivo de su lealtad, y que sọ́lo la pueden recibir como ofensa al verse dispensados de la paga de una cuota que es la más eficaz señal de ella, y que la piedad deP Reyi sólo La conduce ên dos más apurados lances de una tenáziconjuiración,l parano valerse de la autoridad y respeto de sus armas contra unos vasallos que las más de las veces (o casi siempre) no obran como hombres sino como puras máquinas, a quienes dirije la seducción y el engaño". Ante la multiplicidad de las consultas, declaraba el Visitador que el "expresado indulto sólo lo han de disfrutar los indios de las provincias realmente rebeldes al tiempo de su promulgación y de ninguna suerte a los que no han sido nunca, ni menos de las auxiliares que han asistido a nuestros' destacamentos bajo prest". Por aquel tiempo el Virrey conociendo la gran escasez de víveres en la costa y más especialmente en las provincias de la sierra, ordenaba a los' Maes- 
tros de los barcos que realizaban el tráfico con la Capitanía general de Chile, desembarcar alimentos en los puertos' de Intermedios para su internamiento a los territorios en donde existía hambruna.

Cuando el nuevo visitador Escobedo tomaba posesion de su cargo, encontró que los alborotos habian trastornado por completo la hacienda pública. La reconciliación, con mucho de fingimiento y de temor, llevaba en el transfondo múltiples recelos. Numerosas poblaciones, haciendas y minerales estaban destruídos, o lo que se agregaba una "mortandad inexplicable de todas castas". La deuda pública había crecido $\mathrm{y}$ se notaba escasez de hombres. "Como la mortandad de los indios, su fuga y otros accidentes inevitables de la rebelión hacían tan urgentes las revistas, para no dejar incierto el cargo de los Corregiclores, abracé el partido de confiar a ellos mismos' los padrones provisionales, empeñándolos con

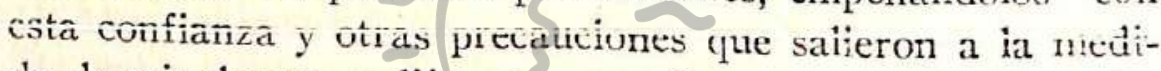
da de mis deseos, y dije que no podian entonces actuarse las matrículas, porque a más de estar muchas provincias del reino conmovidas, hubiera sido arriesgada la diligencia aún en las pacificadas, sino se dejaban afianzar en el sosiego y evitaban otros inconvenientesl queopodrian ser pretexto para perturbarlo en aquel acto"-manifiesta el nuevo Visitador. El intento de hacer tributarios a los Cholos, Mestizos y otras castas, quedaba sin efecto por real cédula en agosto de $I_{7} 83$. $Y$ se descubrió que realizadas las cobranzas honradamente, aumentaron las entradas a pesar de haber disminuício la población - lo que ratificaba la acusación contra los Corregidores.

Al término de la campaña de represión los indios mostraban mucha humildad y solicitud con las autoridades y con las gentes de otras razas, causando admiración. "El contemplar, que después de haber sido, sin excepción, unos contu- 
maces rebeldes contra Dios, contra el Rey y la Patria, se hahían tornado a ser humildes, que me escasean voces, para hacer una viva expresión de su conducta y estado". Dice el presbitero Sawaraura que en su visita hasta la jurisdicción del obispado de la Paz vió a las milicias listas para cualquier emergencia. Las festividades tradicionales, realizadas sin los trajes antiguos. "Ya no hay trajes de Incas, Nustas, bocinas, escofietas (cofia o redecilla) que suelen usar en sus cabezas. El día de San Tiago sacan la Real bandera los incas nobles, vestidos de uniformes o de golilla; ya no llevan las insignias de los Incas ni plumaje" Las ceremonias religiosas mostraban el fervor especial de los indios' atemorizados, concurriendo a las efemérides de los santos titulares y a los' honrados por devoción. Los propietarios vueltos a la posesión de sus' bienes, estaban en plena labor de reparar los gravísimos daños sufridos en las pasadas' luchas. "Las fincas de las iglesias, conventos, monasterios y de otros particulares, se ven hoy en una suma decadencia; que todavía se pasarán años, para rehacerlas. Las quemazones de las casas en los pueblos y otros lugares son muchas, así de parte de los indios, como de las tropas españolas que destrozaban los pueblos. Hay lugares que causan llanto, al ver sus' ruinas".

La vida económica iba reponiéndose con lentitud. La èscasez de víveres hizo que el "maíz, harinas y otras legumbres llegaron a tener mucho precio, lo que nunca", empujando a los indios a salir hasta los caminos para obtenerlos', con tantos "comedimientos y finezas, aunque rústicas, que es imposible que la ley de la gratitud no les compela al agradecimiento de los españoles; a los'sacerdotes y religiosos los distinguen en todo".

El gobierno politico y civil retornaba a los cauces antiguos, perdidos con la presencia de funcionarios colocados por los rebeldes e incapaces de guardar las distancias. Y el caos 
jurídico fué grande, porque cuando la sentencia era desfavorable los indios alzados acudían ante otro juez, como si el anterior no hubiera existido ni los obligase con su fallo. Con la rebelión coincidieron "tantas secas en esta tierra arriba, que es imponderable que aún las lagunas más cuantiosas y ríos caudalosos han llegado casi a secarse, de donde se puede inferir la infertilidad de los campos y golpe de hielos. Han muerto muchísimos sólo de hambre".

Jáuregui fué reemplazado por el virrey don Teodoro de Croix. Nacido en el territorio del antiguo Flandes, habia ejercido el cargo de Comandante general en México, duran. te el gobierno del virrey don Carlos Francisco de Croix. Su entrada en Lima ocurrió el seis de abril de 1784 , permaneciendo en el cargo cerca de seis años - en cuyo lapso murió Carlos III y fué proclamado Carlos IV. (Rel̉evado en marzo de 1790 por don Francisco Gil Taboada y Lemos, Croix retornaba a España, recibiendo la cruz de Carlos III. Falleció en abril de I79r). Gobernaba el virrey Croix cuando se efectuaron dos importantes medidas (reclamadas por Túpac Amaru) : la sustitución de los Corregimientos por las Intendencias, y la erección de la Audiencia del Cusco.

La Ordenanza de Intendentes - aplicada con anterioridad en Buenos Aires -, sustituyó los Corregimientos por las Intendencias, ante el desprestigio general de los Corregidores, y para la mejor recaudación de los Tributos. Los Intendentes eran funcionarios ubicados entre el Virrey y los Subdelegados o autoridades de los Partidos. Croix traía encargo especial de auxiliar al visitador Escobedo en la implantación de las Intendencias y sus autoridades. La Ordenanza de Intendentes quitaba al Virrey la dirección de la Hacienda 
real, poniéndola en manos de un Intendente general dè ejército y hacienda. Los Intendentes tenían jurisdicción en asuntos de Justicia, Policía, Hacienda y Guerra, ejerciendo además el Vicepatronato en lo eclesiástico. La extinción de los Corregimientos se realizaban al término de los' quinquenios. Los repartos mercantiles quedaban definitivamente prohibidos, "entendiéndose que los Indios y demás Vasallos míos de aquellos Dominios quedan, por consecuencia, en libertad ce comerciar donde, y con quien les acomode para surtirse de todo lo que necesiten". Lo dicho, únicamente con respecto al comercio interior.

Siete fueron las Intendencias correspondientes al virreynato del Perú: Lima, Trujillo, Arequipa, Tarma, Huancavelica, Huamanga y Cusco. La de Puno se añadió con posterioridad. (El primero de febrero de 1796 se daba una real cédula en Badajoz, mandando agregar la intendencia de $\mathrm{Pu}$ no "con todo su territorio a ese Virreynato det Perú en los ramos de la Policía, Hacienda y Guerra, y en el de Justicia a la mencionada mi Real Audiencia del Cusco pero sin hacer novedad en cuanto a la Intendencia de Arequipa, cuyo territorio conviene continúe sujeto a esa mi Real Audiencia de Lima").

El virrey Croix expedía los titulos correspondientes a las autoridades, quedando sometidas a una Junta Superier de futura creación. Sin embargo, existió un intento de regresión. La disposición novena de la Ordenanza mandaba explicitamente que los Subdelegados, Alcaldes' ordinarios y Gobernadores no pudieran "repartir". El visitador Escobedo, con aprobación del Virrey, elevó un proyecto ante la Corona, pidiendo que los antiguos Repartos fuesen realizados por e! Tribunal de! Consulado, calculando el beneficio en un mi1!ón. El Rey contestó desaprobando aquella iniciativa, con 1o que se consolidó la reforma. 
La Real Audiencia del Cusco se creaba ei tres de mayo de I 787 en Aranjuez, para "mayor honor, y decoro de la cit1dad del Cusco, antigua Metrópoli del Imperio del Perú, y evitar los' graves perjuicios, y dispendios que se originan a mis vasallos, de recurrir en sus negocios por apelación a mis Realcs Audiencias de Lima y Charcas". Comprendía las provincias correspondientes al obispado del Cusco y las que señalase el virrey Croix, con informe del visitador Escobedo.

Como Regente fué nombrado el oidor de Lima don José de la Portilla, en mayo de 1787 , con un sueldo de nueve mil pesos antales. Tres Oidores y un Fiscal en lo civil y criminal completaban la Audiencia, siendo Primer Oidor don José Resabal y Ugarte, con cuatro mil pesos. El Agente fiscal Relator y Escribano de cámara recibían quimientos pesos. La Escribanía era oficio vendíble y renunciable. Un Capellán con trescientos pesos. Canciller y Registrador y un Repartidor eran oficios vendibles y renunciables, sin gozo de sueldo. Finalmente había un Abogado de pobres, un Procurador, dos Porteros y un Barrendero, con paga del ramo de Penas de cámara.

El nuevo Regente hacia su entrada en la ciudad del Cusco, seguido por lucida comitiva, el veinticuatro de junio de I788. Terminados los oficios en la Catedral pasaba a la casi del Cabildo, señalado como su morada y en donde se instalaría la Real Audiencia. El tres de noviembre ingresaba el Real Sello, en un caballo que "excedia en la grandeza de su ornato, y en la riqueza del texido, y bordado de su aderezo, a quantos tan varia y pomposamente se veian por toda la comparsa" - formada por las autoridades, vecinos principales, nobles indígenas y caciques, vestidos a la usanza española. "Eran agradabilísimos los coloquios de unos con otros: la plebe consigo misma, el vulgo entre los que lo componen, los nobles entre los de su clase, y aún también misturados estos 
órdenes; se oían diálogos ya festivos, ya jocosos, ya serios, ya de dolor por los desórdenes pasados, ya de gozo de la renovación de la Justicia”. Y el cuatro de noviembre, cumpleaños' del rey don Carlos III, tenían lugar las principales ceremonias: misa solemne de gracias, saludo al Regente y actuac'ión extraordinaria en el Colegio real de San Bernardo, dirigicio por su Rector don Ignacio Castro. La conmemoración oficial se completaba mediante fiestas públicas, como fuegos artificiales, corridas de toros, danzas de máscaras y jucgos de caña.

La alarma que producía la rebelión de Túpac Amaru, la preponderancia inglesa adquirida por el tratado de 1783 y el reconocimiento español de la independencia de las' trece colonias norteamericanas sentaban un precedente negativo para el sostenimiento del Imperio colonial español, abriendo los ojos a los politicos perspicaces.

Don Pedro Pablo de Abarca y Bolea conde de Aranda, en su calidad de embajador ycfirmante del tratado de Versalles', enviaba ante Carlos Hufcin Informevecreto, cuyas ideas muestran su penetración y profundo conocimiento históricopolítico, siendo el pasmo de un lector actual. Dirigiéndose al Monarca escribe: "Acabo de firmar y ajustar en virtud de órdenes y poderes' que se ha dignado darme V.M. un tratado de paz con Inglaterra. Esta Negociación que según los testimonios lisonjeros de palabra y por escrito de V.M. debo creer he logrado desempeñar conforme a sus reales intenciones, ha dejaclo en mi alma, debo confesarlo un sentimiento penoso. $\mathrm{La}$ independencia de las colonias inglesas queda reconocida, y este es para mí un motivo de dolor y temor. Francia tiene pocas posesiones en América; pero ha debido considerar que 
España su intima aliada, tiene muchas, y que descle hoy se halla expuesta a las más' terribles conmociones. Desde el principio, ha obrado Francia en contra de sus verdaderos intereses, alentando y apoyando esta independencia, y con frecuencia he declarado así a los ministros de aquella nación. ¿¿đué demás próspero podía acontecer a Francia que ver como sc destruían los ingleses y norte-americanos en una guerra de partido, que no podía menos de aumentar su poder favoreciendo sus intereses?. La antipatía que reina entre Francia e Inglaterra, cegó al gabinete francés que se olvidó de que su interés consistía en permanecer tranquilo expectador de esta lucha: y una vez lanzado en la arena nos comprometió; a consecuencia del pacto de familia, a una guerra completamente contraria a nuestra propia causa. No es este lugar de examinar la opinión de algunos hombres de estado, tanto nacionales como extranjeros, en la cual estoy conforme a cerca de las dificultades de conservar nuestro dominio en América. Jamás han podide conservarse por mucho tiempo posesiones tan vastas, colocadas a tan gran distancia de las metrópolis. A esta causa general a todas las colonias hay que agregar otras especiales a las posesiones-españolas, a saber: ia dificultad de enviagesocorrós hecesarios; tas vejaciones de algunos gobernadores para sus desgraciados habitantes; la distancia que los separa de la autoridad suprema a que pueden recurrir pidiendo el desagravio de sus ofensas, lo cual es causa de que a veces transcurran años de que se atiendan a sus reclamaciones: las venganzas a que permanecen expuestas mientras tanto por parte de las autoridades locales; la dificultad de conocer bien la verdad a tan gran distancia; y finalmente, los medios que los virreyes y gobernadores como españoles, no pueden dejar de tener para obtener manifestaciones favorables a España; circunstancias que reunidas todas', no pueden menos que descontentar a los habitantes de 
América, moviéndolos a hacer esfuerzos a fin de conseguir la independencia tan luego como la ocasión lo sea propicia. Asi pues, sin entrar en ninguna de estas consideraciones me ceñiré en la actualiclad a la que nos ocupa relativamente: al temor de vernos expuestos a serios peligros por parte de la nueva potencia que acabamos de reconocer, en un país en que no existe ninguna otra en estado de cortar su vuelo. Esta República Federal nació pigmea por decirlo así, y ha necesitado del apoyo y fuerzas de dos estados tan poderosos' como España y Francia para conseguir la independencia. Llegará un día en que crezca y se torne gigante y aún coloso temible en aquellas' regiones. Entonces olvidará los beneficios que ha recibido de las dos potencias y sólo pensará en su engrandecimiento. La libertad de conciencia, la facilidad de establecer una población nueva en terrenos inmensos, así como las ventajas de un gobierno naciente, les atraerá agricultores y artesanos de todas las naciones; y dentro de pocos años veremos con vercladero dolor la existencia tiránica de este coloso de que voy hablando. El primer paso de esta potencia, cuando haya logrado engrandecimiento, será apoderarse de las Floridas a fin de dominar el golfo de México. Después de molestarnos así y nuestras relaciones con la Nueva España, aspirará a la conquista de este vasto imperio, que no podremos defender contra una potencia formidable, establecida en el mismo continente y vecina suya. Estos temores son muy fundados señor; y deben de realizarse dentro de breves años' sino presenciamos otras conmociones más funestas en nuestra América. Justifica este modo de pensar lo que ha acontecido en todos los' siglos y en todas las naciones que han empezado a engrandecerse. Doquiera el hombre es' el mismo; la diferencia de los climas no cambió la naturaleza de nuestros sentimientos, y el que encuentra ocasión de adquiric poder y elevarse no la desperdicia jamás. ¿Cómo podremos, pués, pro- 
meternos que los norte-americanos respeten al reino de Nueva España, cuando tengan medios de apoderarse de aquel rico y hermoso país?. Un político cuerda nos aconseja que tomemos precauciones contra los males que puedan sobrevenir. Este pensamiento ocupó toda mi atención desde que como Ministro Plenipotenciario de V. M. y conforme su voluntad real e instrucciones', firmó la paz de París, estudiando negocio tan importante con todo cuidado de que soy capaz; y después de muchas reflexiones q' me han sugerido los' conocimientos, tanto militares como políticos que he podido adquirir en mi larga carrera, creo firmemente que no nos queda para evitar las grandes pérdidas' que nos amenazan, más que el recurso que voy a tener la honra de exponer a V.M."

"A fin de realizar este gran pensamiento de un modo que convenga a España, deben de establecerse tres infantos en América, uno como rey de México, otro como rey del Perú, y otro como rey de Costa Firme, tomando V. M. el título de emperador. Las concesiones de esta inmensa cesión podrían ser que los tres nuevos reyes y sus sucesores, reconociesen a V. M. y a los príncipes que ocupen el trono después por jefes supremos de las familias, que el rey de México pagase cada año como feudo por la cesion de aquel reino, una contribución en plata de un número determinado de marcos, que se enviarian en barras para acuñarlos en las casas de Moneda de Madrid y Sevilla. Lo misno haría el rey del Perú, pagando en oro de sus posesiones. El de la Costa Firme remitiría cada año su contribución en géneros coloníales, sobre todo en Tabaco, para abastecer los estancos del reino. Estos soberanos y sus hijos, deberían casarse siempre con infantas de España o de su familia, y los príncipes españoles se enlazarían con princesas de los reinos de Ultramar. De este modo se establecería una unión íntima entre las cuatro coronas, y antes de sentarse en el trono cualquiera de estos soberanos de- 
berían jurar solemnemente que cumpliría con estas condiciones. El comercio habría de hacerse bajo el pié de la más estricta reciprocidad, debiendo considerarse las' cuatro naciones como unidas por la más estrecha alianza ofensiva y defensiva para su conservación y prosperidad. No hallándose nuestras fábricas en estado de abastecer a América de todos los objetos manufacturados de que pudiera tener necesidad, sería preciso que Francia aliada nuestra, les suministrase todos los' artículos que nos viéramos nosotros imposibilitados de enviar, con exclusión absoluta de Inglaterra. Para este fin, los tres soberanos al sentarse en sus tronos respectivos, ajustarían tratados' formales de comercio con España y Francia, cuidando muchos de excluir a los ingleses. Como poseedores de nuevos estados, podrían hacer libremente lo que más les conviniera".

"De la ejecución de semejante plan resultarian las ventajas siguientes: la contribución de los tres reinos del Nuevo Mundo sería mucho más provechoso para España que los socorros en dinero en que la actualidad envía América: la población aumentaría cesando la emigración continua a tan lejanas posesiones: y una vez estrechamente unidos los tres reinos de Américą por medio de las obligaciones propuestas. no hay en Europa potencia que pudiera igualarse a su poder ni al de España y Francia en nuestro continente. Al mismo tiempo habría fuerza para impedir el engrandecimiento de las colonias americanas, o el de cualquiera otra potencia que quisiera establecerse en aquella parte del mundo. Con la unión de los nuevos reinos y España, el comercio español cambiaría los productos nacionales por los' géneros coloniales que pudiéramos necesitar para nuestro consumo. Por este medio se aumentaría nuestra marina mercante y la militar por consiguiente sería respetada en todos los mares. Las' islas que arriba he citado, administrándolas bien y poniéndolas en 
buen estado de defensa, nos bastarían para nuestro comercio, sin necesidad de otras pos'esiones, y finalmente disfrutaríamos, de todas las ventajas que nos da la posesión de América sin ninguno de sus inconvenientes". Hasta aquí, el conde de Aranda.

En tiempo de Carlos IV, el valido don Manuel Godoy exponía un proyecto similar. El pensamiento de Godoy era "que en lugar de virreyes fuesen nuestros infantes a la América, que tomasen el título de príncipes regentes, que se hiciesen amar allí, que llenasen con su presencia la ambición y el orgullo de aquellos naturales, que les acompañas'e un buen consejo con ministros responsables, que gobernase allí con ellos un senado, mitad de Americanos y mitad de Españoles, que se mejoras'en y acomodaran a los tiempos las leyes de Indias, y que en los negocios del país se terminasen y fuesen fenecidos en tribunales propios de cada cual de estas regencias, salvo sólo aquellos' casos en que el interés común de la metrópoli y de los pueblos de la América requiriese terminarlos en Europa". Y aunque Godoy lo niega, su proyecto aparece como una simple variante de actuella original iniciativa del conde de Aranda.

(Jorgranda.

Carlos Valcárcel. 


\section{BIBLIOGRAFIA}

Dooumentos para la Historia de la sublevación de Túpac Amaru. (Col P. Angẹlis). 1. ${ }^{a}$ edición 1836. 2. ${ }^{a}$ edición 1910. Buenos Aires. (Odriozola transcribe la $1 .^{a}$ edición en el T. I. de sus Doeumentos históricos).

La verdad desnuda. (Col. Loayza, serie I, tomo III). Lima, 1943. Estado del Perú, por R. J. Sahuaraura. (Col, Loayza, serie I, tomo V). Lima, 1944. (Esta obra contiene además el Epistolario del obispo Moseoso).

Documentos sobre la rebelión de Túpac Amaru. (Publicado por Carlos Valcáreel). Bol. de U. de San Mareos, Nos. 3-4. Lima, 1944. Libros de Reales céduł.as y órdenes desde 1760. Arch. del Minist. de Hacienda y Comercio, No. 1063a.

Túpac Amaru, el rebelde, por B. Lewin. Buenos Aires 1943, (Trae un Apéndice con 58 documentos).

Relación del virrey Jáuregui.c (Col. Lorente, tomo III). Madrid, 1872. (Este tomo contiene un oficio del visitador Eseobedo al ministro Gálvez, y la memoria del virrey Guirior).

Relación sobire los hechos más notables de la sublevación de Túpac Amaru.-Rev. Archivos y Bibliotecas. Volumen V. Lima, 1900.

Ordenes del subdelegado Ordozgoyti.-Rev. Archivos y Bibliotecas, Vol. IV. Lima, 1900.

Relación de la fundación de la Audiencia del Cusco, por Ignacio de Castro. Madrid, 1795.

Real Ordenanza para el establecimiento de Intendentes. Madrid 1782.

Carta a los españoles americanos, por Juan Pablo Vizcardo y Guzmán. Bol. Museo Bolivariano, No. 9. Lima, 1928.

Relación del virrey Croix. (Col. M. A. Fuentes, tomo V). Lima, 1859.

La Gran Bretaña y la independencia del Perú, por R. Porras Barrenechea. Bol. Museo Bolivariano, No. 8. Lima, 1929. 
Rebeliones indígenas en Lima durante la Colonia. Rev. Históriea, tomo IX. Lima, 1935.

Historia del Perú bajo los Borbones, por S. Lorente. Lima, 1871.

El pueblo en la revolución americana, por Luis Azberto Sánchez, Buenos Aires, 1942.

Memoria de Manuel Godoy, tomo III. Gerona, 1839.

Informe secreto del Conde de Aranda al Rey Carlos III. Documentos literarios del Perú, Col. Odriozola, t. VII.-Imp. del Estado. Lima, 1875. Págs. 535_39.

El pseudo Memorial de Aranda en 1783, por Arturo P. Whitaker. -II. Congreso Internacional de Historia de América, t. II.Tall. J. Peuser. Buenos Aires, 1938. Págs. 549-58.

La rebelión del eacique Túpac Amaru, por Carlos Valcárcel (inédito).-Tit. II, cap. $90^{\circ}$; tit. IV, eap. 30 .

Documentos inéditos en poder del señor Franeisco A. Loayza: De Areche a la Corte sobre restrieción a los indios y prohibición de la Historia escrita por Garcilaso de la Vega, por perjudicial 1-V-781.-Del gobierno españolal Virrey del Perú ordenando recoger los ejemplares de la Historia eserita por el Inca Garcilaso de la Vega 1-VIII-783. Tomado del Archivo de Indias, Sección Audiencia del Cusco, legajo No. 29.

Nота. Esta bibliografía ha sirlo zutilizada para-los partes referentes a los Sintomas y a las Consecuencias. La Introdueción y Sinópsis está basada en una bíbliografia mayor, cuya insereión sería pedante en el artículo presente. 